$\begin{array}{ll}\text { Research Square } & \begin{array}{l}\text { Preprints are preliminary reports that have not undergone peer review. } \\ \text { They should not be considered conclusive, used to inform clinical practice, } \\ \text { or referenced by the media as validated information. }\end{array}\end{array}$

\title{
GSTM1 and GSTT1 Double Null Genotypes Determining Cell Fate and Proliferation as Potential Risk Factors of Relapse in Children with Hematological Malignancies after Stem Cell Transplantation.
}

\author{
Simona Jurkovic Mlakar \\ University of Geneva Medical Centre: Universite de Geneve Faculte de Medecine \\ Chakradhara Rao Uppugunduri Satyanarayana \\ University of Geneva Medical Centre: Universite de Geneve Faculte de Medecine \\ Tiago Nava \\ University of Geneva Medical Centre: Universite de Geneve Faculte de Medecine \\ Vid Mlakar \\ University of Geneva Medical Centre: Universite de Geneve Faculte de Medecine \\ Hadrien Golay \\ University of Geneva Medical Centre: Universite de Geneve Faculte de Medecine \\ Shannon Robin \\ University of Geneva Medical Centre: Universite de Geneve Faculte de Medecine \\ Nicolas Waespe \\ University of Geneva Medical Centre: Universite de Geneve Faculte de Medecine \\ Mohamed-Ali Rezgui \\ CHU Sainte-Justine: Centre Hospitalier Universitaire Sainte-Justine \\ Yves Chalandon \\ University of Geneva Medical Centre: Universite de Geneve Faculte de Medecine \\ Jaap Jan Boelens \\ University of Utrecht: Universiteit Utrecht \\ Robbert G.M Bredius \\ Leiden University Medical Center: Leids Universitair Medisch Centrum \\ Jean-Hugues Dalle \\ Hospital Robert Debre: Hopital Robert Debre \\ Christina Peters \\ S. Anna Hospital: S Anna hospital \\ Selim Corbacioglu \\ University of Regensburg: Universitat Regensburg \\ Henrique Bittencourt \\ CHU Sainte-Justine: Centre Hospitalier Universitaire Sainte-Justine \\ Maja Krajinovic \\ CHU Sainte-Justine: Centre Hospitalier Universitaire Sainte-Justine \\ Marc Ansari ( $\triangle$ marc.ansari@hcuge.ch ) \\ Geneve University Hospitals: Hopitaux Universitaires Geneve
}

\section{Research}

Keywords: Null-genotypes of Glutathione S-transferases, acute leukemia, hematological malignancies, hematopoietic stem cell transplantation, posttransplant relapse, busulfan resistance, necrosis, apoptosis, glutathione

Posted Date: May 7th, 2021

DOI: https://doi.org/10.21203/rs.3.rs-439729/v2

License: @ (i) This work is licensed under a Creative Commons Attribution 4.0 International License. Read Full License 


\section{Abstract}

Background: Relapse is the major cause of treatment failure in children with hematological malignancies (HMs) undergoing busulfan (BU)- based allogeneic hematopoietic stem cell transplantation (HSCT). Glutathione S-transferases (GSTs) isoforms that participate in BU detoxification and protect cells against stress and cell death may be linked to post-HSCT outcomes. This study aimed to retrospectively evaluate the genetic association of null variants of Glutathione S-transferases GSTM1 and GSTT1 with relapse incidence in children with HMs undergoing BU-containing allogeneic HSCT and to assess the impact of these variants on BU-induced cytotoxicity on the immortalized and tumor lymphoblastoid cell lines (LCLs).

Methods: GSTM1- and GSTT1- null alleles were genotyped using germline DNA from whole blood prior to a conditioning BU-based regimen. Association of GSTM1-and GSTT1- null variants with relapse incidence was analyzed using multivariable competing risk analysis. BU-induced cell-death studies were conducted in GSTs- null and non-null LCLs and CRISPR-Cas9 gene-edited THP1 leukemia cell lines.

Results: Carrying GSTM1/GSTT1 double null genotype was found to be an independent risk factor for post-HSCT relapse in 86 children (adjusted HR: 6.52 [95\% Cl, $\left.2.76-15.42 ; \mathrm{p}=1.9 \times 10^{-5}\right]$ ). BU induced cell death preferentially in THP1 ${ }^{\text {GSTM1 (non-null) } \text { and LCLs }}{ }^{\text {GSTM1 (non-null) }}$ as shown by decreased viability, increased necrosis and levels of the oxidized form of glutathione compared to null cells, while GSTT1 non-null cells showed increased baseline proliferation.

Conclusion: The clinical association suggests that GSTM1/GSTT1 double null genotype could serve as genetic stratification biomarker for the high risk of post-HSCT relapse. Functional studies have indicated that GSTM1 status modulates BU-induced cell death. On the other hand, GSTT1 is proposed to be involved in baseline cell proliferation.

Trial registration: ClinicalTrials.gov identifier: NCT01257854, Registered February 2008 - retrospectively registered.

\section{Background}

Survival rates of children with hematological malignancies (HMs) undergoing allogeneic hematopoietic stem-cell transplantation (HSCT) have improved over the years achieving $91 \%$ estimated two-year overall survival. The improvement is mainly attributed to reduced HSCT-related toxicity and mortality. The incidence of post-HSCT relapse remains a significant complication and varies from 12-33\% after two years (1). Risk factors that influence transplant success are on the one hand host- and disease-related, such as disease genetics and remission status before HSCT, and on the other hand, transplant-related, such as conditioning regimen and treatment-related toxicities including for example severe graft-versus-host disease (GvHD), sinusoidal obstruction syndrome (SOS), and infections (2-4).

A bifunctional alkylating agent Busulfan (BU) is still often used in conditioning regimens prior to HSCT in children and adolescents (5) and is commonly administered along with other chemotherapeutics, e.g. cyclophosphamide (CY), and fludarabine (FLU) $(6,7)$. At least in acute myeloid leukemia (AML), BU has shown lower long-term adverse effects consequently replacing total body irradiation (TBI) in the conditioning regimen (8). In acute lymphoblast leukemia $(A L L)$, although the recently published results showing lower rates of relapse after TBI-containing conditioning, the results obtained with BU in association with FLU and thiotepa were encouraging and indicate an opportunity to find genetic subgroups of patients who might beneficiate from the TBI-free conditioning (1).

BU is metabolized via conjugation with glutathione (GSH) in the liver, which is predominantly catalyzed by glutathione S-transferase alpha1 (GSTA1) (9). In hematopoietic cells (HCs), where GSTA1 is not expressed (10), other GST isoenzymes, particularly Mu1 (GSTM1, 46\% of the BU conjugating activity of GSTA1 (9)) might play the most important role. The role of GSTT1 in BU conjugation is not yet known but has been mostly reported to have combined effects with GSTM1 on clinical outcomes $(11,12)$. In addition to their protective role of the conjugation of BU in HCs, they might contribute to multiple cellular processes such as regulation of cell proliferation and apoptosis through the interaction with protein kinases such as apoptosis signal-regulating kinase 1 (ASK1). Under stress conditions, the interaction of the GSTM1:ASK1 complex is dissociated and results in activation of ASK1 that activates the c-Jun N-terminal kinase (JNK) and mitogen-activated protein kinase p38 (MAPK p38) pathways, leading to upstream cytokine-and stress-induced apoptosis (13, 14). However, the impact of apoptosis through kinases on BU-dependent cytotoxicity is poorly understood and even less whether those GST genes naturally knocked down might interfere in the post-HSCT relapse potential.

GSTM1 and GSTT1 genes can be homozygously deleted (presented as GSTM1-null and GSTT1-null) and thus completely deprived of the enzyme activities in a high percentage of individuals (the average \% in Europe are 51 and 19, respectively) (15). In AML adult patients, Weiss et al. (16) showed a perfect concordance of those variants in malignant and germ-line DNA, which suggests that the germline genotype drives protein expression in malignant cells. Although these variants have been associated with a higher risk of leukemia development (17), there are conflicting reports on the association of the GSTM1null and GSTT1-null variants with relapse in patients with HMs (18-21). To date, there is no evidence available for the association of germline GSTM1-null and GSTT1-null variants with post-HSCT relapse in children with HMs.

Because GSTM1 and GSTT1 are the main remaining GSTs in HCs, we hypothesized that the absence of either or both proteins should affect BU cytotoxicity through conjugation -dependent or -independent ways, interfering in the HSCT outcomes. Hence, a genetic association study based on germline GSTT1-and GSTM1-null variants was undertaken. Further, we conducted in vitro functional analyses to understand the role of these variants in survival and BU-induced apoptosis and necrosis of the immortalized and tumor lymphoblastoid cell lines (LCLs).

\section{Materials And Methods}




\section{Patients and treatment}

Pediatric patients with ALL, AML or myelodysplastic syndrome (MDS) who had undergone allogeneic HSCT between 2000-2013 were enrolled in the study. The Institutional Review Board or ethics committees approved the study and all patients and/or parents provided informed consent. The present study is a subset of the multicentric study under the umbrella of the European Society for Blood and Marrow Transplantation (EBMT) (Clinicaltrials.gov identifier: NCT01257854) (22).

I.v. BU (Busulfex, Otsuka Pharmaceuticals, Saint-Laurent, Montreal, QC, Canada or Busilvex, Pierre Fabre Laboratory, Paris, France) administration was given as a $2 \mathrm{~h}$ infusion to the patients, every $6 \mathrm{~h}$ for a total of 16 doses. The first BU dose was age- and weight-based and pharmacokinetic (PK)-guided dose adjustment was performed in order to obtain a cumulative area under the curve (CumAUC) between 59.2-98.56 mg*h/L as reported previously (22).

The primary diagnosis of HMs was made at the referring institution. Patients were considered to be in remission after chemotherapy if they presented $<5 \%$ blasts in the normal cellular bone marrow. Relapse in MDS was defined as $>5 \%$ and $\leq 20 \%$ of blasts at the bone marrow examination after engraftment and/or reappearance of major dysplastic features associated with cytopenias and/or mixed chimerism $>5 \%$ and/or detection of the same cytogenetic abnormality present at diagnosis. Relapse in AML and ALL was defined as the presence of blasts in the bone marrow $>5 \%$, confirmed by flow cytometry; detection of the gene fusion present at diagnosis; or according to minimal residual disease (MRD) results after the transplantation if available. Disease remission status was defined by the number of bone marrow remission or relapse events before HSCT.

Cumulative relapse incidence was defined according to the standard guidelines of EBMT and as detailed in our recent report (22).

\section{Genotyping and statistical analysis}

Genotyping of GSTM1-null and GSTT1-null variants was performed on germline DNA, extracted from whole blood or peripheral mononuclear cells of all patients before the first HSCT as described by Lin et al. (23).

Pearson Chi-Square test was used to analyze the differences in demographics between groups with and without GST -null variants. Estimated cumulative relapse incidence by competing risk analysis with non-relapse mortality as a competing event and the difference among groups were estimated by Gray's test (24). The Fine-Gray model was used for competing risk regression in multivariable analysis to obtain adjusted $p$-values for all the variables in relation to the genotype groups (25). The potential risk factors with a p-value $\leq 0.25$ in the univariable competing risk analysis were retained in the multivariable analysis by including the GST genotype factor with the lowest p-value. The final multivariable analysis included: diagnosis (ALL, AML and MDS), disease status [1st complete remission (CR), a higher degree of CRs and absence of CR], conditioning regimen (standard regimen with two alkylating agents and intensified regimen with three alkylating agents), AUC after the first dose of Busulfan (1st BU dose AUC categorized into below 3.7, between 3.7 and 6.16, and above 6.16 $\mathrm{mg}$ h/L) and BU CumAUC (below 59.2, between 59.2 and 98.6, and above $98.6 \mathrm{mg}$ h/ $\mathrm{L}$ ) as categorical variables.

All statistical analyses on clinical data were performed using SPSS (RRID: SCR_002865, Version 24.0. Armonk, NY: IBM Corp.) and R Project for Statistical Computing (version 3.6.2, RRID: SCR_001905) with Rcmdr package (version 2.6.1). Statistical power calculations according to GST-variants were conducted in G*Power - Statistical Power Analyses for Windows and Mac, version 3.1.9.2 (RRID: SCR_013726; Dusseldorf, Germany).

\section{In vitro functional studies of the associated variants Cell models design and cell characterization}

A set of 56 immortalized non-malignant lymphoblastoid cell lines (LCLs), acquired in 2012 from International HapMap Consortium`s CEPH Families Reference Panel 142011/147712 (Coriell Cell Repository, Camden, NJ, USA), and a human monocytic leukemia cell line (THP1; acquired in 2018 from ATCC, Cat\# TIB202, RRID: CVCL_0006; Manassas, Virginia, USA), derived from a 1-year old patient, were used for baseline and BU-induced functional assessment of GSTM1null and GSTT1-nullvariants. The cells were immediately stored at $-196^{\circ} \mathrm{C}$ and were not used prior to the start of experiments. The cell lines were thawed and cultured in Roswell Park Memorial Institute Medium (RPMI) 1640 medium (Gibco, Carlsbad, CA) supplemented with 10\% fetal bovine serum (HyClone, South Logan, UT) and $1 \%$ Penicillin-Streptomycin (Gibco) and incubated at $37^{\circ} \mathrm{C}, 5 \% \mathrm{CO}_{2}$-humidified atmosphere according to manufacturer's recommendations. The number of passages between thawing and use in each in vitro experiment achieved the range between 5- and 15-times. The IDs of investigated LCLs used for each particular in vitro experiment are listed in Supplementary Table 1.

THP1 GSTM1- and GSTT1- knock out cell lines (THP1 ${ }^{\text {GSTM1 }(-/-)}$ and THP1 ${ }^{\text {GSTT1 }}{ }^{-(-)}$) were prepared from parental THP1 representing non-null genotype for

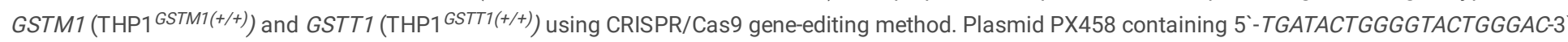
gRNA (GSTM1) or 5'-TGAAGGACGGGGACTTCACC-3` gRNA (GSTT1) (prepared by GeneScript, The Netherlands) was transfected into THP1 cells. 10,000 cells were fluorescence-activated cell sorted (FACS) in 24-well plates based on the presence of green fluorescence protein (GFP) $48 \mathrm{~h}$ post-transfection. After 48 to $72 \mathrm{~h}$ of recovery, THP1 cells were single-cell cloned in 96-well plates using FACS. Gene-modified clones were genotyped for the presence of deleterious mutations using Sanger sequencing and confirmed by Western blot for the success of gene knockout. Five clones of the same genotype were pooled in a population.

DNA and proteins of the selected cell lines (LCLs, THP1 ${ }^{\text {GSTM1(-/-) }}$ and THP1 ${ }^{\text {GSTT1(-/-) }}$ cell models) were extracted using DNeasy Blood and Tissue Kit (Qiagen, Hilden, Germany) and standard protein extraction protocol for western blot using RIPA lysis buffer (Sigma-Aldrich, Germany), respectively. The intracellular concentration of extracted proteins was measured using Bradford assay from Bio-Rad (Hercules, CA) according to the manufacturer's recommendations. Loading [MathJax]/jax/output/CommonHTML/fonts/TeX/fontdata.js jent and LDS sample buffer (Thermo Fisher Scientific, USA) were subjected to electrophoresis by 
using Invitrogen Novex Tris-Glycine Gels (Thermo Fisher Scientific, USA). Dry transfer to a nitrocellulose membrane was performed with the iBlot dry blotting system (Thermo Fisher Scientific, USA). A membrane was blocked using $5 \%$ milk in PBS and $0.05 \%$ Tween 20 . The following primary antibodies were used for protein labeling: ß-Actin Mouse monoclonal antibody (Abcam Cat\# ab6276, RRID: AB_2223210); GSTP1 Monoclonal Antibody Rabbit (DSHB Cat\# CPTCGSTP1-1, RRID: AB_2617266); GSTM1 Monoclonal Antibody Mouse (Thermo FisherScientific Cat\# MA5-17085, RRID: AB_2538556) and GSTT1 Polyclonal antibody Rabbit (Thermo FisherScientific Cat\# PA5-22011, RRID: AB_11154445). Lumi-Light WB Substrate (Roche, CH) was used for the detection of the secondary antibody linked with horseradish peroxidase (HRP). Band intensities were identified using Syngene G-Box System (Syngene, Frederick, MD, USA).

The glutathione transferase activity (Glutathione S-transferase [GST] Assay Kit, Sigma Aldrich, USA) was measured on cell lysates obtained from one million cells (THP1 ${ }^{\text {GSTM1 } 1(-/)}$ and THP1 ${ }^{\text {GSTM1(+/+) }}$ by measuring absorbance at $340 \mathrm{~nm}$ every minute for 10 minutes in a $200 \mu$ l well of a $96-$ well plate using Spectramax ID3 Multi-Mode microplate reader (Molecular Devices, USA) according to the manufacturer's recommendations. GST activity was calculated as the following: $[\Delta 340 \mathrm{~nm}(\mathrm{~min})$ * total volume of the reaction $(\mathrm{ml})] /\left[5.3 \mathrm{mM}^{-1}\right.$ * volume of enzyme] corrected according to the protein concentration in $\mathrm{mg} / \mathrm{ml}$ obtained by using a Pierce ${ }^{\text {TM }}$ BCA Protein Assay Kit (Thermo Fisher Scientific, USA) according to manufacturer`s guidelines.

The results of the characterization of CRISPR-Cas9 THP1 gene-edited cell models with target proteins (GSTM1, GSTT1 and GSTP1) and GST activity are presented in Supplementary Fig. 1 (A, B and C).

DNA samples from LCLs were genotyped for GSTM1-null and GSTT1-nullvariants using multiplex real-time PCR amplification in the presence of SYBR Green I and genotype discrimination by melting curve analysis in a StepOnePlus ${ }^{\mathrm{TM}}$ Real-Time PCR System (Applied Biosystems ${ }^{\mathrm{TM}}$, Foster City, CA, USA) with BCL2 (BCL2 apoptosis regulator) gene as an internal control as described earlier (26). The genotyping method used cannot differentiate the heterozygous individuals from homozygous non- null carriers (furtherly marked as GSTM1(+) and GSTT1(+)) except when using Sanger sequencing.

\section{Cell viability, Apoptosis, Necrosis, GSSG/GSH measurements, and Caspase activities}

Intracellular ATP concentrations (CellTiter 2.0 Luminescent Cell Viability Assay (Promega Corporation, Madison, WI)) were screened in 56 LCLs and CRISPR-

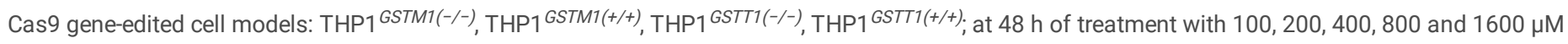
concentrations of BU (Sigma-Aldrich, Germany) reconstituted with DMSO (Sigma), $1 \%$ of DMSO (as control) and at baseline (medium only). For validation of the first screening, ATP-independent cell viability follow-up (72 h) was performed at BU concentrations of 100, 250 and $500 \mu \mathrm{M}$ in three GSTM1(+) and four GSTM1(-/-) LCLs (Supplementary Table 1) and at baseline in THP1 ${ }^{\text {GSTT1(-/-) }}$ and THP1 ${ }^{\text {GSTT1 } 1(+/+)}$ using RealTime-Glo ${ }^{\text {MT }}$ Cell Viability Assay (Promega, USA).

Annexin V/PI assay (BD Biosciences) was used to measure live, early and late apoptotic and necrotic cells. Prior to FACS, ten GSTM1(+) and ten GSTM1(-/-) LCLs (Supplementary Table 1) were treated for $48 \mathrm{~h}$ with BU (1\% DMSO) at 250, 500 and $1000 \mu \mathrm{M}$ and two samples of each cell line were used as controls (1\% DMSO and untreated). One million cells were labeled according to the manufacturer's protocol. FACS analysis was performed using the CyAN ADP system (Beckman Coulter, UK). Results were analyzed by Kaluza analysis software, version 1.3 (Beckman Coulter, UK). Apoptosis and necrosis were followed for 72h in six GSTM1(+) and six GSTM1(-/-) LCLs (Supplementary Table 1) treated with $500 \mu \mathrm{M}$ BU using RealTime-Glo MTAnnexin V Apoptosis and Necrosis Assay (Promega).

Concentrations of the total (GSH $)$ (GSH-Glo Glutathione Assays, Promega, USA) and oxidized intracellular glutathione (GSSG) (GSH/GSSG-Glo Glutathione Assays, Promega, USA) were measured according to the manufacturers' recommendations. Prior to measurement, cells from five GSTM1(+) and five GSTM1(-/-) LCLs and CRISPR-Cas9 gene-edited THP1 cell models were incubated for $48 \mathrm{~h}$ at $500 \mu \mathrm{M} \mathrm{BU}$ and $1 \%$ DMSO (control). Results are expressed as the relative proportion of GSSG to $\mathrm{GSH}_{\mathrm{T}}$.

Caspase-Glo 3/7 assay (Promega) was used to measure the total activity of caspases -3 and -7 in a subset of 12 LCLs (Supplementary Table 1) and CRISPR-Cas9 gene-edited THP1 cell models at $48 \mathrm{~h}$ BU post-treatment $(250,500$ and $1.000 \mu \mathrm{M})$.

Chemiluminescent signals were measured using Victor3 (Perkin Elmer, Inc, USA). All BU-based data were normalized relative to the negative controls with 1\% DMSO.

\section{Statistical analyses in in-vitro functional studies}

The cell-based experiments $\left(\mathrm{IC}_{50}\right.$ distribution, end-point apoptosis and necrosis, real-time monitoring of viability, apoptosis and necrosis, Caspase3/7 activities; and [GSSG/GSH $]$ ratios) were performed at least in duplicates and results are reported as observed means \pm SD stratified by GST-null and GST-nonnul/variants. Statistical differences between genotypes were assessed using Mann-Whitney, t-tests, or two-way ANOVA according to the normality of the distribution and compared to untreated controls using GraphPad Prism 7 software (RRID: SCR_002798). We considered $p<0.05$ to be statistically significant in all analyses.

\section{Results}

\section{GSTM1- and GSTT1- double null genotypes are associated with higher relapse incidence.}

Eighty-six children with malignancies aged 5 months - 18 years (female/male, 44/42), who received myeloablative conditioning containing with four-timesdaily i.v. BU followed by HSCT, were enrolled in this study. The patients' baseline characteristics at the time of their HSCT are summarized in Table 1. The number of patients who had experienced relapse was 16 (18.6\% of included patients) with the median time to onset 203 days (range 35 to 817$)$ and 12

Loading [MathJax]/jax/output/CommonHTML/fonts/TeX/fontdata.js 
(14.0\%) patients died with the median time to onset 221 days (range 15 to 979 ). The median CumAUC of BU achieved $56.96 \mathrm{mg} \star \mathrm{h} / \mathrm{L}$ (concentration range 30.50-115.23 mg*h/L).

Regarding the genotype frequency, 49 patients were GSTM1-null (57.0\%), 24 GSTT1-null (27.9\%) and 9 had null genotypes in both GSTM1 and GSTT1 genes (10.5\%). Characteristics of these patients according to GSTM1-null and GSTT1-null variants are shown in Supplementary Table 2.

Relapse was associated with GSTT1-null compared to GSTT1-non-null subgroups (42.1\% vs $16.1 \%)$ in the univariable analysis ( $p=0.04$, Fig. $1 \mathrm{~A}$, Table $2 \mathrm{~A})$. The GSTM1-null was not associated with relapse (Fig. 1B, Table 2A). However, patients carrying null genotypes in both GSTM1 and GSTT1 genes showed significantly increased risk of relapse compared to other genotype subgroups ([GSTM1-non-null/GSTT1-non-null, GSTM1-non-null/GSTT1-null and GSTM1null/GSTT1-non-nul]; $\mathrm{p}=0.012$, Fig. 1C, Table 2A) and this risk remained significant when other genotype subgroups were grouped together (using a genegene interaction model; $77.8 \%$ vs 19.0\%; $\mathrm{p}=0.002$, Fig. 1D, Table 2B). Relapse was compared between GSTM1-null and GSTT1-null variants combined with other possible risk factors (Table 2B). GSTM1/GSTT1-double null status was independently associated with relapse with an HR of 6.52 [95\% Cl, 2.76-15.42; $\mathrm{p}$ $\left.=1.9 \times 10^{-5}\right]$.

\section{LCL sensitivity to BU is associated with GSTM1 but not with GSTT1 genotypes}

Significantly higher cell viability after treatment with BU was observed in LCLs with GSTM1-null genotype (1.8-fold, p = 0.013) and THP1 ${ }^{\text {GSTM1(-/-) }}$ cells (1.5fold, $\mathrm{p}=0.0006$ ) compared to GSTM1-non null by $48 \mathrm{~h}$ endpoint (Figs. $2 \mathrm{~A}$ and $2 \mathrm{~B}$, respectively) and the results were confirmed by $72 \mathrm{~h}$ - kinetic measurements in LCLs (Supplementary Fig. 2). GSTT1-null, alone or in combination with GSTM1-null, did not show a significant association with BU-IC ${ }_{50}$ in LCLs and THP1 ${ }^{\text {GSTT1 }(-/-)}$ cell lines (Fig. 2C and 2D, respectively). No difference in baseline cell proliferation was seen between GSTM1-null and GSTM1-non-null cells (Fig. 3A), while the proliferation of GSTT1-null cells was significantly decreased in comparison to GSTT1-non-null carriers in LCLs carrying GSTT1-null genotype and THP1 ${ }^{\text {GSTT1 }(-/-)}\left[\mathrm{p}=0.03\right.$ (LCL, 48h end-point measurement, Fig. 3B) and $\mathrm{p}<0.05$ (THP1 ${ }^{\text {GSTT1 }(-/-)}$, 72h kinetic plot, Fig. 3C)].

\section{GSTM1 -null genotype is associated with increased apoptosis and decreased primary necrosis after BU- treatment}

In a subgroup of ten GSTM1-nul/ LCLs, we observed increased early apoptosis and a decreased primary necrosis ( $p=0.026$ and 0.006 , respectively) at $48 \mathrm{~h}$ post-treatment with 250, 500 and $1000 \mu \mathrm{M}$ of BU in comparison to ten GSTM1-non-nul/ LCLs (Figs. 4A to D). No significant differences between both GSTM1 genotype groups were observed for the number of live cells and apoptotic cells at a later stage (the mix of necrotic and real apoptotic cells). Apoptosis was further assessed through measurement of Caspase 3/7 activity according to GST(-/-) variants showing significantly higher activation in GSTM1-nul/ LCLs and THP1 ${ }^{\text {GSTM1(-/-) }}$ at 250, 500 and $1000 \mu \mathrm{M} \mathrm{BU}$ in comparison to GSTM1-non-null cells ( $\mathrm{p}<0.05$; Fig. 4E), while no differences were observed at baseline. BUinduced activation of Caspase $3 / 7$ was not significant in GSTT1-nul/LCLs $(p=0.21)$, while in THP1 ${ }^{G S T T 1}(-/-)$ was significantly decreased $(p=0.002$; Fig. 4E) in comparison to GSTT1-non null cells.

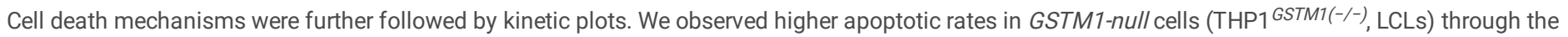
whole $72 \mathrm{~h}$ of follow-up after BU treatment when compared to GSTM1-non-null cells from unrelated individuals (Supplementary Figs. 3A and 3C, $\mathrm{p}<0.0001$ and $p=2.6 \mathrm{E}-05$, respectively). In contrast, we observed lower necrotic rates in GSTM1-null cells (THP1 GSTM1(-/-), LCLs) that were increasing after $26 \mathrm{~h}$ of BU treatment when compared to GSTM1-non null cells (Supplementary Figs. 3B and 3D, p $<0.001$ and 1.4E-05, respectively). Apoptosis at the same time- points was lower in these cells accounting for the faster cell death mainly as the result of primary necrosis.

\section{4. [GSSG/GSH ${ }_{T}$ ] ratios are higher in GSTM1-non-null LCLs and THP1 ${ }^{\text {GSTM1(+/+) }}$ cells after BU- treatment compared to GSTM1-null while total GSH levels remain unchanged.}

At baseline, no differences in [GSSG/GSH $]$ ratios were observed between null and non-null LCLs and THP1 cells for the GSTM1 gene. However, $48 \mathrm{~h}$ after 500 $\mu \mathrm{M}$ BU treatment, [GSSG/GSH ] ratios were increased 1.6- $(\mathrm{p}=0.02, \mathrm{LCLs})$ and 1.3- fold ( $\mathrm{p}=0.005$, THP1) in GSTM1 non-null compared to GSTM1-null (Figs. 5A and C, respectively). A similar trend was observed after the $250 \mu \mathrm{M} \mathrm{BU}$ treatment (48h) in THP1 ${ }^{\text {GSTM1 }(-/ /)}$ in comparison to THP1 ${ }^{\text {GSTM1(+/+) }}$ cells (Fig. 5C). In THP1, no significant difference was observed according to GSTT1 genotype after the treatment with BU or at baseline (Fig. 5D). In addition, we observed a significant increase in total GSH levels after the $500 \mu \mathrm{M} \mathrm{BU}$-treatment, irrespective of the GSTM1 genotype (Fig. 5B, $\mathrm{p}=0.001)$, thus indicating the potential for BU-related induction of GSH synthesis.

\section{Discussion}

Our clinical association study performed in 86 children with HMs undergoing HSCT following BU-based conditioning regimens demonstrated that patients harboring homozygous deletions in both GSTM1 and GSTT1 genes presented a high risk of relapse (HR 7.2 [95\% Cl, $2.2-23.9 ; \mathrm{p}=0.002])$. After adjustment for known risk factors (diagnosis, disease status, the intensity of conditioning regimen and BU exposure), the association remained significant demonstrating that the deletion of both GST genes is an independent risk factor for relapse (adjusted HR 6.52 [ $\left.95 \% \mathrm{Cl}, 2.8-15.4 ; \mathrm{p}=1.9 \times 10^{-5}\right]$ ). Although it is a small cohort, this is the first report on the risk of post-HSCT relapse in relation to the germ-line GSTM1-and GSTT1-nul/variants in children with HMs. Until now, only one study conducted in BU/CY-based HSCT settings although in adults showed increased relapse rates in patients carrying GSTM1-null genotype, while no association Loading [MathJax]/jax/output/CommonHTML/fonts/TeX/fontdata.js non-transplant-based studies in pediatric or adult patients, a similar association between

Page 5/19 
GSTM1/GSTT1 double null carriers and increased risk of relapse $(19,28-30)$, lower complete remission rate (31) and lower event-free survival was demonstrated $(18,19,32-38)$. There are nevertheless a few studies showing no such an association $(20,39)$, in which the small number of patients or the different treatment regimens may have mainly precluded defining a relationship between GST variants.

Based on the known detoxifying role of GSTs, our results from the clinical association are contradictory. Although GSTA1 is the main enzyme involved in BU detoxification, GSTM1 is also highly expressed in the liver and recognized as involved in BU conjugation $(9,11,22,40)$, precluding the BU to cross-link with the DNA strands. Functional variants of the genes coding for GSTs may then interfere in HSCT by affecting BU metabolism. It is known that low BU exposure (CumAUC $<59 \mathrm{mg} \times \mathrm{h} / \mathrm{L}$ ) is associated with graft failure and relapse $(5,22,41)$ whereas high BU exposure (CumAUC > $98.6 \mathrm{mg} \times \mathrm{h} / \mathrm{L})$ could reduce post-HSCT relapse in leukemia at the cost of an increase in organ toxicities, and therefore transplantation-related mortality $(5,22,41-43)$. However, at the level of HCs, less is known about the direct effect of $\mathrm{BU}$.

We compared BU-related cell death mechanisms in LCLs and THP1 with and without GSTM1 and/or GSTT1 genes after exposure to BU. We demonstrated that only GSTM1-null (but not GSTT1-null) is associated with higher resistance to BU as determined by higher BU-IC 50 values of GSTM1-null LCLs and

THP1 (GSTM1- - ) in comparison to GSTM1-non-null cells. This could be due to a change in the redox equilibrium as demonstrated by lower levels of oxidized GSH, lower primary necrosis and higher early apoptosis. An increase of GSTM1-null LCL's viability was confirmed either by continuous follow-up of redox potential within $72 \mathrm{~h}$. Apoptosis/necrosis kinetic results demonstrate that BU-induced apoptotic processes are more pronounced in GSTM1-null LCLs. In contrast, primary necrotic cell death was more pronounced in GSTM1-non-null cells when comparing with the GSTM1 -null cells. In addition, primary necrosis was significantly induced at an earlier stage in GSTM1-non-null cells. These results show that GSTM1-null variants can modulate BU-induced cell death, which were supplemented further by increased activation of known apoptotic markers Caspase -3 or -7 in GSTM1-null LCLs and THP1 in comparison to GSTM1-nonnull cells. Importantly, observed reduced rates of GSTM1-dependent cell death cannot be attributed to the increased baseline cell proliferation.

The findings of higher primary necrosis, lower early apoptosis and lower cell viability in GSTM1-non-null hematopoietic cells compared to GSTM1-null cells treated with BU were unexpected. Contrary to our observations, many studies showed associations between increased expression or activity of GSTs and resistance mechanisms against a range of cytotoxic drugs $(44,45)$. These results could potentially be explained by not only direct detoxification with GSH but also through negative regulation of pro-apoptotic protein kinases, such as apoptosis signal-regulating kinase 1 (ASK1) (13, 14). For instance, stress conditions cause the release of ASK1 from GSTM1, thereby leading to induction of apoptosis, which was shown in our experiments after induction with BU. In addition, GSTM1-null cells carrying more free ASK1 for phosphorylation activation are expected to have more apoptosis upon BU-induced stress in comparison to GSTM1-null cells which is in accordance with our in vitro results.

However, the observed paradox in increased cell death of GSTM1 well expressed cells upon BU treatment could additionally be explained by findings of the study of DeLeve et al. (46) demonstrating that in murine hepatocytes BU is cytotoxic also through oxidative stress caused by BU metabolites (BU glutathione S- conjugate thiophenium ion, GS ${ }^{+} \mathrm{THT}$ ) and by the depletion of GSH in addition to DNA alkylation. The toxic metabolites of BU/GSH metabolism are mainly oxidized by Flavin-containing monooxygenases (FMOs, e.g. FMO3) and cytochromes (CYPs, e.g. CYP3A4) (47) to water-soluble non-toxic metabolites (e.g. sulfolane, (48)). However, CYP3A4 and FMO3 are mainly expressed in the liver (accounting for 54\% of overall tetrahydrothiophene [THT] disappearance, the metabolite of $\mathrm{BU}$ ), and less in LCLs, as observed in our laboratory (data not shown) and by others (https://www.proteinatlas.org). After RNA sequencing in LCLs, very low or no gene expressions of $C Y P 2 D 6,2 C 19,2 C 9,2 B 6,2 C 8,4 A 11,3 A 4, F M O 1$ and $F M O 3$ were identified. In this context, the oxidative burst caused by electrophilic molecules from BU-GSH conjugation $(49,50)$ in addition to the absence of CYP3A4 and FMO3 could be a reason for the lower sensitivity of GSTM1-null HCs to BU, as observed in LCLs and THP1. In contrast, higher total expressions of CYPs and FMOs in hepatocytes (47) could explain why GSTA1slow BU metabolizing individuals in addition to the absence of GSTM1 activity show potentially more treatment-related toxicities (e.g. SOS (51) and aGvHD (52)) than carriers with normal GST's enzyme activities. A hypothetical comparative model of the difference in BU fate between hepatocytes and lymphocytes is suggested in Supplementary Figure 4 and warrants further investigation.

The genetically-determined different cell fate after BU exposure might explain the apparently discordant results between the relapse incidence in patients carrying GSTM1-null genotype (in combination with GSTT1-null) and the cellular resistance to BU in GSTM1 null-LCLS and THP1 GSTM1(- - ). The higher rates of necrosis in GSTM1-non null cells might predict a pro-inflammatory cell death of the malignant cells, resulting in enhanced immunogenicity (53). Unlike the other chemotherapeutic regimens including autologous transplantation, the efficacy of the allogeneic transplantation relies on the graft-versus-leukemia effect, especially in HMs $(54,55)$, but that theory should be further explored.

Another relevant observation is the significantly increased post-HSCT relapse in GSTT1-null when combined with GSTM1-null genotype in children with HMs. The link between GSTT1 and post-HSCT relapse is not clear yet. Our in vitro observations cannot be attributed to the BU-related differences in IC ${ }_{50}$ values or [GSSG/GSH $\mathrm{GH}_{\mathrm{T}}$ ratios. Other pharmacogenomics studies also demonstrated that genetic variations in GSTT1 are not associated with BU clearance or liver toxicity $(11,51,56,57)$. Nevertheless, we observed faster baseline proliferation in GSTT1-non-null LCLs/THP1 and a slightly higher baseline increase of Caspase 3/7 activation compared to those with GSTT1-nul/ genotype, indicating GSTT1 potential involvement of BU- independent mechanisms in the relapse development.

The results of the present clinical study are limited by the retrospective study design and relatively small pediatric sample size with no clinical validation cohort. However, the sample size of 86 patients has at least $80 \%$ power with $10 \%$ of observed combined GSTM1/GSTT1 double nul/variants frequency and relapse incidence with the estimated observed effect size of $\geq 7.0$ and alpha value of 0.05 . The primary diagnosis of HMs was made at the referring institution and was not centrally reviewed. Well-known risk factors such as somatic genetic/cytogenetics abnormalities, the donor DNA and the initial response to the treatment (e.g. MRD) were not available. However, as described in Supplementary Table 2 similar characteristics were present between the GST genetic subgroups ( $\mathrm{p}$-values > 0.05). The GST-nul/ variants were not associated with the status of the disease before HSCT and we are assuming that the Loading [MathJax]/jax/output/CommonHTML/fonts/TeX/fontdata.js ent in malignant cells as shown by Weiss et al. (16). The majority of cases in our study underwent a 
BU-CY conditioning regimen, however, it is not known if this association is specific to a BU-CY conditioning regimen only or unspecific to other chemotherapeutics used in HSCT setting (e.g.Thio or Mel) (7). For instance, active metabolites of CY (e.g. acrolein) are also eliminated by GSH conjugation catalyzed by GSTs (48). This needs to be evaluated in the future with a focus on whether GSTs play a major role in determining clinical outcomes. This aspect is currently being evaluated by our group using a cohort from multiple centers with the usage of multiple conditioning regimens. Furthermore, the transplantrelated mortality or combined toxicities were not associated with the GSTM1-and GSTT1-null variants (data are not shown), suggesting compensation of BU conjugation by other GSTs, especially GSTA1, which is mainly expressed in hepatocytes and other somatic cells.

\section{Conclusions}

In summary, we report that GSTM1/GSTT1 double null genotypes could serve as genetic biomarkers for identifying pediatric patients with HMs at higher risk of relapse after an allogeneic HSCT following BU-containing conditioning. On the other hand, the absence of those markers might predict the patients who more likely will respond to the chemotherapy-based conditioning. Functional studies indicated different mechanisms of cell death upon exposure to BU based on the presence or absence of GST-null alleles and the in vivo impact of those findings must be further explored.

\section{Abbreviations}

Acute lymphoblast leukemia (ALL)

Acute myeloid leukemia (AML)

Analysis of variance (ANOVA)

Apoptosis signal-regulating kinase 1 (ASK1)

BCL2 (BCL2 apoptosis regulator)

Busulfan (BU; 1,4-butanediol dimethanesulfonate)

bone marrow (BM)

$\mathrm{BU}$ glutathione S- conjugate thiophenium ion $\left(\mathrm{GS}^{+} \mathrm{THT}\right)$

C-Jun N-terminal kinase (JNK)

Clustered regularly interspaced short palindromic repeats (CRISPR)

Complete remission (CR)

Cord blood (CB)

Cyclophosphamide (CY)

Cytochromes (CYPs)

Cumulative area under the curve (CumAUC)

Deoxyribonucleic acid (DNA)

Dimethyl sulfoxide (DMSO)

European Society for Blood and Marrow Transplantation (EBMT)

Flavin-containing monooxygenases (FMOs)

Fludarabine (FLU)

Fluorescence-activated cell sorted (FACS)

Y-glutamyldehydroalanylglycine (EdAG)

Glutathione (GSH)

Glutathione S-transferase (GST)

Glutathione S-transferase alpha1 (GSTA1)

Glutathione S-transferase mu1 (GSTM1) 
Glutathione S-transferase tau1 (GSTT1)

Graft-versus-host disease (GvHD)

Green fluorescence protein (GFP)

Hazard ratio (HR)

Hematological malignancies (HMs)

Hematopoietic stem cell transplantation (HSCT)

Human monocytic leukemia cell line (THP1)

$50 \%$ inhibitory concentration $\left(\mathrm{IC}_{50}\right)$

identical unrelated HLA match compatibility (MUD)

Intra venous (I.v.)

Lymphoblastoid cell lines (LCLs)

Melphalan (Mel)

Minimal residual disease (MRD)

mitogen-activated protein kinase P38 (MAPK p38)

Myelodysplastic syndrome (MDS)

non-identical related HLA match compatibility (MMRD)

non-identical unrelated HLA match compatibility (MMUD)

Oxidized intracellular glutathione (GSSG)

peripheral blood stem cells (PBSCs)

pharmacokinetic (PK)

Polymerase chain reaction (PCR)

Reactive oxygen species (ROS)

Roswell Park Memorial Institute Medium (RPMI)

Sinusoidal obstruction syndrome (SOS)

Tetrahydrothiophene (THT)

Thiotepa (Thio)

Total glutathione $\left(\mathrm{GSH}_{\mathrm{T}}\right)$

Total body irradiation (TBI)

\section{Declarations}

\section{Ethics approval and consent to participate}

The Institutional Review Board or ethics committees approved the study and all patients and/or parents provided informed consent.

\section{Consent for publication}

Not applicable

\section{Availability of data and material}

Loading [MathJax]/jax/output/CommonHTML/fonts/TeX/fontdata.js dy are available from the corresponding author on reasonable request. 


\section{Competing interests}

The authors declare that they have no competing interests related to the submitted work.

\section{Funding}

This study was performed thanks to the contribution of the Swiss National Science Foundation (ME9870/320030-153389, PI: Marc Ansari), the OAK foundation (OCAY-17-642, PI: Marc Ansari) and the CANSEARCH foundation (PI: Marc Ansari).

\section{Authors`contributions}

SJM, CRSU, MA designed the study; SJM, VM, CRSU executed cell viability experiments; SJM, CRSU isolated DNA/mRNA and genotyping from cell lines; SJM, VM contributed to apoptosis and necrosis-based experiments and produced CRISPR-Cas9 THP1 knock out cell models; SJM executed real-time viability and apoptosis/necrosis, caspase $3 / 7$ and GSH -based experiments, western-blotting and bioinformatics

analysesofRNAsequenc $\in$ gdatausingIPA; SJM, CRSU, SR: GSTactivity; MA, MAR, YC, JJB, RGMB, JHD, CP, SC, HB, MKcontributed $\rightarrow$ patiel sample and clinical data processing; SJM executed computational and statistical analysis of clinical data that were verified by MA, TN, CRSU, HB; SJM, MA, VM, TN, CRSU contributed to interpretation of results; SJM drafted the manuscript; all authors revised the study critically. MA had final responsibility for the decision to submit for publication. All the authors read and approved the final manuscript.

\section{Acknowledgements}

We warmly thank the patients and their parents for consenting to participate in this study. We also thank Laurence Lesne, Mary Khoshbeen, Denis Marino, Rodolfo Lo Piccolo, Benedict Dupraz, Anuj Kumar Tyagi and Eva Choong for the help in this study as well as the Swiss Pediatric Oncology Group.

\section{References}

1. Peters C, Dalle JH, Locatelli F, Poetschger U, Sedlacek P, Buechner J, et al. Total Body Irradiation or Chemotherapy Conditioning in Childhood ALL: A Multinational, Randomized, Noninferiority Phase III Study. J Clin Oncol. 2021;39(4):295-307.

2. Hamilton BK, Copelan EA. Concise review: the role of hematopoietic stem cell transplantation in the treatment of acute myeloid leukemia. Stem Cells. 2012;30(8):1581-6.

3. Barrett AJ, Battiwalla M. Relapse after allogeneic stem cell transplantation. Expert Rev Hematol. 2010;3(4):429-41.

4. Shah NN, Borowitz MJ, Steinberg SM, Robey NC, Gamper CJ, Symons HJ, et al. Factors predictive of relapse of acute leukemia in children after allogeneic hematopoietic cell transplantation. Biol Blood Marrow Transplant. 2014;20(7):1033-9.

5. Philippe M, Goutelle S, Guitton J, Fonrose X, Bergeron C, Girard P, et al. Should busulfan therapeutic range be narrowed in pediatrics? Experience from a large cohort of hematopoietic stem cell transplant children. Bone Marrow Transplant. 2016;51(1):72-8.

6. Ciurea SO, Andersson BS. Busulfan in hematopoietic stem cell transplantation. Biol Blood Marrow Transplant. 2009;15(5):523-36.

7. Hao C, Ma X, Wang L, Zhang W, Hu J, Huang J, et al. Predicting the presence and mechanism of busulfan drug-drug interactions in hematopoietic stem cell transplantation using pharmacokinetic interaction network-based molecular structure similarity and network pharmacology. Eur J Clin Pharmacol. 2020.

8. Lee CJ, Kim S, Tecca HR, Bo-Subait S, Phelan R, Brazauskas R, et al. Late effects after ablative allogeneic stem cell transplantation for adolescent and young adult acute myeloid leukemia. Blood Adv. 2020;4(6):983-92.

9. Czerwinski M, Gibbs JP, Slattery JT. Busulfan conjugation by glutathione S-transferases alpha, mu, and pi. Drug Metab Dispos. 1996;24(9):1015-9.

10. Czerwinski M, Kiem HP, Slattery JT. Human CD34+ cells do not express glutathione S-transferases alpha. Gene Ther. 1997;4(3):268-70.

11. Kim SD, Lee JH, Hur EH, Lee JH, Kim DY, Lim SN, et al. Influence of GST gene polymorphisms on the clearance of intravenous busulfan in adult patients undergoing hematopoietic cell transplantation. Biol Blood Marrow Transplant. 2011;17(8):1222-30.

12. Myers AL, Kawedia JD, Champlin RE, Kramer MA, Nieto Y, Ghose R, et al. Clarifying busulfan metabolism and drug interactions to support new therapeutic drug monitoring strategies: a comprehensive review. Expert Opin Drug Metab Toxicol. 2017;13(9):901-23.

13. Board PG, Menon D. Glutathione transferases, regulators of cellular metabolism and physiology. Biochim Biophys Acta. 2013;1830(5):3267-88.

14. Tew KD, Townsend DM. Glutathione-s-transferases as determinants of cell survival and death. Antioxid Redox Signal. 2012;17(12):1728-37.

15. Saitou M, Ishida T. Distributions of the GSTM1 and GSTT1 null genotypes worldwide are characterized by latitudinal clines. Asian Pac J Cancer Prev. 2015;16(1):355-61.

16. Weiss JR, Baer MR, Ambrosone CB, Blanco JG, Hutson A, Ford LA, et al. Concordance of pharmacogenetic polymorphisms in tumor and germ line DNA in adult patients with acute myeloid leukemia. Cancer Epidemiol Biomarkers Prev. 2007;16(5):1038-41.

17. Li M, Zheng M, Chen H, Yu H. Effects of GST variants on the risk odds of hematological malignancy: A meta-analysis. J Cell Biochem. 2018.

18. Stanulla M, Schrappe M, Brechlin AM, Zimmermann M, Welte K. Polymorphisms within glutathione S-transferase genes (GSTM1, GSTT1, GSTP1) and risk of relapse in childhood B-cell precursor acute lymphoblastic leukemia: a case-control study. Blood. 2000;95(4):1222-8.

Loading [MathJax]/jax/output/CommonHTML/fonts/TeX/fontdata.js 
19. Takanashi M, Morimoto A, Yagi T, Kuriyama K, Kano G, Imamura T, et al. Impact of glutathione S-transferase gene deletion on early relapse in childhood Bprecursor acute lymphoblastic leukemia. Haematologica. 2003;88(11):1238-44.

20. Franca R, Rebora P, Basso G, Biondi A, Cazzaniga G, Crovella S, et al. Glutathione S-transferase homozygous deletions and relapse in childhood acute lymphoblastic leukemia: a novel study design in a large Italian AIEOP cohort. Pharmacogenomics. 2012;13(16):1905-16.

21. Balta G, Yuksek N, Ozyurek E, Ertem U, Hicsonmez G, Altay C, et al. Characterization of MTHFR, GSTM1, GSTT1, GSTP1, and CYP1A1 genotypes in childhood acute leukemia. Am J Hematol. 2003;73(3):154-60.

22. Ansari M, Curtis PH, Uppugunduri CRS, Rezgui MA, Nava T, Mlakar V, et al. GSTA1 diplotypes affect busulfan clearance and toxicity in children undergoing allogeneic hematopoietic stem cell transplantation: a multicenter study. Oncotarget. 2017;8(53):90852-67.

23. Lin DX, Tang YM, Peng Q, Lu SX, Ambrosone CB, Kadlubar FF. Susceptibility to esophageal cancer and genetic polymorphisms in glutathione Stransferases T1, P1, and M1 and cytochrome P450 2E1. Cancer Epidemiol Biomarkers Prev. 1998;7(11):1013-8.

24. Gray RJ. A Class of K-Sample Tests for Comparing the Cumulative Incidence of a Competing Risk. Ann Stat. 1988;16(3):1141-54.

25. Fine JP, Gray RJ. A proportional hazards model for the subdistribution of a competing risk. J Am Stat Assoc. 1999;94(446):496-509.

26. Marin F, Garcia N, Munoz X, Capella G, Gonzalez CA, Agudo A, et al. Simultaneous genotyping of GSTT1 and GSTM1 null polymorphisms by melting curve analysis in presence of SYBR Green I. J Mol Diagn. 2010;12(3):300-4.

27. Terakura S, Onizuka M, Fukumoto M, Kuwatsuka Y, Kohno A, Ozawa Y, et al. Analysis of glutathione S-transferase and cytochrome P450 gene polymorphism in recipients of dose-adjusted busulfan-cyclophosphamide conditioning. Int J Hematol. 2020;111(1):84-92.

28. Borst L, Buchard A, Rosthoj S, Wesolowska A, Wehner PS, Wesenberg F, et al. Gene dose effects of GSTM1, GSTT1 and GSTP1 polymorphisms on outcome in childhood acute lymphoblastic leukemia. J Pediatr Hematol Oncol. 2012;34(1):38-42.

29. Barragan E, Collado M, Cervera J, Martin G, Bolufer P, Roman J, et al. The GST deletions and NQ01*2 polymorphism confers interindividual variability of response to treatment in patients with acute myeloid leukemia. Leuk Res. 2007;31(7):947-53.

30. Xiao Q, Deng D, Li H, Ye F, Huang L, Zhang B, et al. GSTT1 and GSTM1 polymorphisms predict treatment outcome for acute myeloid leukemia: a systematic review and meta-analysis. Ann Hematol. 2014;93(8):1381-90.

31. Xiao Z, Yang L, Xu Z, Zhang Y, Liu L, Nie L, et al. Glutathione S-transferases (GSTT1 and GSTM1) genes polymorphisms and the treatment response and prognosis in Chinese patients with de novo acute myeloid leukemia. Leuk Res. 2008;32(8):1288-91.

32. Hall AG, Autzen P, Cattan AR, Malcolm AJ, Cole M, Kernahan J, et al. Expression of mu class glutathione S-transferase correlates with event-free survival in childhood acute lymphoblastic leukemia. Cancer Res. 1994;54(20):5251-4.

33. Chen CL, Liu Q, Pui CH, Rivera GK, Sandlund JT, Ribeiro R, et al. Higher frequency of glutathione S-transferase deletions in black children with acute lymphoblastic leukemia. Blood. 1997;89(5):1701-7.

34. Woo MH, Shuster JJ, Chen C, Bash RO, Behm FG, Camitta B, et al. Glutathione S-transferase genotypes in children who develop treatment-related acute myeloid malignancies. Leukemia. 2000;14(2):232-7.

35. Zhang HY, Zhang J, Wu T, Bai H. [Polymorphism of Glutathione S-Transferases and Genetic Sensitivity of Childhood Acute Lymphoblastic Leukemia: A Meta-Analysis]. Zhongguo Shi Yan Xue Ye Xue Za Zhi. 2017;25(1):16-23.

36. Leonardi DB, Abbate M, Riccheri MC, Nunez M, Alfonso G, Gueron G, et al. Improving risk stratification of patients with childhood acute lymphoblastic leukemia: Glutathione-S-Transferases polymorphisms are associated with increased risk of relapse. Oncotarget. 2017;8(1):110-7.

37. Rocha JC, Cheng C, Liu W, Kishi S, Das S, Cook EH, et al. Pharmacogenetics of outcome in children with acute lymphoblastic leukemia. Blood. 2005;105(12):4752-8.

38. Teachey DT, Hunger SP. Predicting relapse risk in childhood acute lymphoblastic leukaemia. Br J Haematol. 2013;162(5):606-20.

39. Zareifar S, Monabati A, Saeed A, Fakhraee F, Cohan N. The association of glutathione S-transferase gene mutations (including GSTT1 and GSTM1) with the prognostic factors and relapse in acute lymphoblastic leukemia. Pediatr Hematol Oncol. 2013;30(6):568-73.

40. Bremer S, Floisand Y, Brinch L, Gedde-Dahl T, Bergan S. Glutathione Transferase Gene Variants Influence Busulfan Pharmacokinetics and Outcome After Myeloablative Conditioning. Ther Drug Monit. 2015;37(4):493-500.

41. Bartelink IH, Lalmohamed A, van Reij EM, Dvorak CC, Savic RM, Zwaveling J, et al. Association of busulfan exposure with survival and toxicity after haemopoietic cell transplantation in children and young adults: a multicentre, retrospective cohort analysis. Lancet Haematol. 2016;3(11):e526-e36.

42. McCune JS, Gooley T, Gibbs JP, Sanders JE, Petersdorf EW, Appelbaum FR, et al. Busulfan concentration and graft rejection in pediatric patients undergoing hematopoietic stem cell transplantation. Bone Marrow Transplant. 2002;30(3):167-73.

43. McCune JS, Holmberg LA. Busulfan in hematopoietic stem cell transplant setting. Expert Opin Drug Metab Toxicol. 2009;5(8):957-69.

44. Hoban PR, Robson CN, Davies SM, Hall AG, Cattan AR, Hickson ID, et al. Reduced topoisomerase II and elevated alpha class glutathione S-transferase expression in a multidrug resistant $\mathrm{CHO}$ cell line highly cross-resistant to mitomycin C. Biochem Pharmacol. 1992;43(4):685-93.

45. Smith MT, Evans CG, Doane-Setzer P, Castro VM, Tahir MK, Mannervik B. Denitrosation of 1,3-bis(2-chloroethyl)-1-nitrosourea by class mu glutathione transferases and its role in cellular resistance in rat brain tumor cells. Cancer Res. 1989;49(10):2621-5.

46. DeLeve LD, Wang X. Role of oxidative stress and glutathione in busulfan toxicity in cultured murine hepatocytes. Pharmacology. 2000;60(3):143-54.

47. El-Serafi I, Terelius Y, Abedi-Valugerdi M, Naughton S, Saghafian M, Moshfegh A, et al. Flavin-containing monooxygenase 3 (FMO3) role in busulphan metabolic pathway. PLoS One. 2017;12(11):e0187294.

48. Uppugunduri CRS, Storelli F, Mlakar V, Huezo-Diaz Curtis P, Rezgui A, Theoret Y, et al. The Association of Combined GSTM1 and CYP2C9 Genotype Status with the Occurrence of Hemorrhanic. Cvstitis in Pediatric Patients Receiving Myeloablative Conditioning Regimen Prior to Allogeneic Hematopoietic Stem Loading [MathJax]/jax/output/CommonHTML/fonts/TeX/fontdata.js

Page $10 / 19$ 
Cell Transplantation. Front Pharmacol. 2017;8:451.

49. Zmorzynski S, Swiderska-Kolacz G, Koczkodaj D, Filip AA. Significance of Polymorphisms and Expression of Enzyme-Encoding Genes Related to Glutathione in Hematopoietic Cancers and Solid Tumors. Biomed Res Int. 2015;2015:853573.

50. Udensi UK, Tchounwou PB. Dual effect of oxidative stress on leukemia cancer induction and treatment. J Exp Clin Cancer Res. 2014;33:106.

51. Srivastava A, Poonkuzhali B, Shaji RV, George B, Mathews V, Chandy M, et al. Glutathione S-transferase M1 polymorphism: a risk factor for hepatic venoocclusive disease in bone marrow transplantation. Blood. 2004;104(5):1574-7.

52. Elhasid R, Krivoy N, Rowe JM, Sprecher E, Adler L, Elkin H, et al. Influence of glutathione S-transferase A1, P1, M1, T1 polymorphisms on oral busulfan pharmacokinetics in children with congenital hemoglobinopathies undergoing hematopoietic stem cell transplantation. Pediatr Blood Cancer. 2010;55(6):1172-9.

53. Sachet M, Liang YY, Oehler R. The immune response to secondary necrotic cells. Apoptosis. 2017;22(10):1189-204.

54. Yeshurun M, Weisdorf D, Rowe JM, Tallman MS, Zhang MJ, Wang HL, et al. The impact of the graft-versus-leukemia effect on survival in acute lymphoblastic leukemia. Blood Adv. 2019;3(4):670-80.

55. Horowitz MM, Gale RP, Sondel PM, Goldman JM, Kersey J, Kolb HJ, et al. Graft-versus-leukemia reactions after bone marrow transplantation. Blood. 1990;75(3):555-62.

56. Gaziev J, Nguyen L, Puozzo C, Mozzi AF, Casella M, Perrone Donnorso M, et al. Novel pharmacokinetic behavior of intravenous busulfan in children with thalassemia undergoing hematopoietic stem cell transplantation: a prospective evaluation of pharmacokinetic and pharmacodynamic profile with therapeutic drug monitoring. Blood. 2010;115(22):4597-604.

57. Goekkurt E, Stoehlmacher J, Stueber C, Wolschke C, Eiermann T, lacobelli S, et al. Pharmacogenetic analysis of liver toxicity after busulfan/cyclophosphamide-based allogeneic hematopoietic stem cell transplantation. Anticancer Res. 2007;27(6C):4377-80.

\section{Tables}

\section{Table 1.}

Demographic and transplantation characteristics of pediatric patients at the time of HSCT and events follow-up 


\begin{tabular}{|c|c|c|}
\hline Variables & & $N(\%)$ \\
\hline Sex & & \\
\hline & Male & $42(48,8)$ \\
\hline & Female & $44(51,2)$ \\
\hline Ethnicity & & \\
\hline & Caucasian & $68(79,1)$ \\
\hline & Other & $18(20,9)$ \\
\hline Diagnosis & & \\
\hline & ALL & $12(14,0)$ \\
\hline & AML & $43(50,0)$ \\
\hline & MDS & $31(36,0)$ \\
\hline stem cell & & \\
\hline & BM & $35(40,7)$ \\
\hline & $\mathrm{CB}$ & $47(54,7)$ \\
\hline & PBSCs & $4(4,7)$ \\
\hline Regimen & & \\
\hline & Busulfan/Cyclophosphamide & $64(74,4)$ \\
\hline & Busulfan/Melphalane & $2(2,3)$ \\
\hline & Busulfan/Cyclophosphamide/Melphalane & $13(15,1)$ \\
\hline & Busulfan/Cyclophosphamide/Etoposide & $7(8,1)$ \\
\hline Serothera & & \\
\hline & No & $31(36,0)$ \\
\hline & ATG & $55(64,0)$ \\
\hline HLA matc & & \\
\hline & MRD & $28(32,6)$ \\
\hline & MUD & $19(22,1)$ \\
\hline & MMRD & $3(3,5)$ \\
\hline & MMUD & $36(41,9)$ \\
\hline Disease $p$ & & \\
\hline & CR1 & $38(44,2)$ \\
\hline & CR2 & $10(11,6)$ \\
\hline & CR3 or more * & $9(10,5)$ \\
\hline & Never treated & $24(27,5)$ \\
\hline & ND & $5(5,8)$ \\
\hline
\end{tabular}




\section{Median (range)}

$\begin{array}{ll}\text { Age at HSCT (years) } & 6,5(0,5-18,2) \\ \text { Weight }(\mathrm{kg}) & 24,5(6,0-87,9) \\ \text { Height }(\mathrm{cm}) & 122,5(51,0-183,0)\end{array}$

Abbreviations: ALL, acute lymphoblastic leukemia; $\mathrm{AML}$, acute myeloid leukemia; BM, bone marrow; BU, busulfan; $\mathrm{CB}$, cord blood; CR1, first complete remission; CR2, second complete remission; CR3, third complete remission; HLA identical sibling; MDS, myelodysplastic syndrome; MMUD, non-identical unrelated; MMRD, non-identical related; MUD, identical unrelated; MRD, identical related; ND, no data; PBSCs, peripheral blood stem cells;

* disease phase "CR3 or more" included all patients either in CR3 or more or in partial remission or those with $>10 \%$ of circulating myeloblasts before conditioning;

\# 2 alkylating agents (busulfan with cyclophosphamide or melphalan) and 3 agents (busulfan/cyclophosphamide with melphalan or etoposide); The enrolled patients were from CHU St Justine (Montreal, Quebec, Canada), The Hospital for Sick Children (Toronto, Ontario, Canada), Robert Debré University Hospital (Paris, France), Leiden University Medical Center (Leiden, Netherlands) and Geneva University Hospital (Geneva, Switzerland).

Table 2(A)

Relationship between GSTM1-null and GSTT1-nul/ variants and other risk factors with a cumulative incidence of relapse in univariable and multivariable competing risk analyses (Fine-Gray`s test)

\begin{tabular}{|c|c|c|c|}
\hline \multirow[b]{2}{*}{ Covariable } & \multicolumn{3}{|c|}{ Univariable analysis } \\
\hline & HR & $95 \% \mathrm{Cl}$ & P-value (CRisk) \\
\hline \multicolumn{4}{|l|}{ GSTM1 genotype } \\
\hline & & & 0.372 \\
\hline $\operatorname{GSTM1}(+)^{(N=37)}$ & Reference & 1 & \\
\hline $\operatorname{GSTM1}(-/-)(N=49)$ & 1.627 & $(0.586-4.514)$ & \\
\hline \multicolumn{4}{|l|}{ GSTT1 genotype } \\
\hline & & & 0.040 \\
\hline $\operatorname{GSTT1}(+)^{(N=62)}$ & Reference & 1 & \\
\hline $\operatorname{GSTT1}(-/-)^{(N=24)}$ & 2.822 & $(1.058-7.528)$ & \\
\hline \multicolumn{4}{|l|}{ GSTM1 and GSTT1 genotypes (4 groups) } \\
\hline & & & 0.012 \\
\hline $\operatorname{GSTM1}(+)$ and GSTT1 $(+)^{(N=22)}$ & Reference & 1 & \\
\hline $\operatorname{GSTM1}(-/-)$ and GSTT1 $(-/-)^{(N=9)}$ & 12.836 & $(2.218-74.274)$ & \\
\hline $\operatorname{GSTM1}(-/-)$ and $\operatorname{GSTT1}(+)^{(N=40)}$ & 1.879 & $(0.378-9.354)$ & \\
\hline GSTM1(+) and GSTT1(-/-)(N=15) & 2.614 & $(0.478-14.300)$ & \\
\hline
\end{tabular}

Table 2 (B) 


\begin{tabular}{|lllllll}
\hline & \multicolumn{2}{c}{ Univariable analysis } & & \multicolumn{3}{c}{ Multivariable analysis } \\
\hline Covariable & HR & $95 \% \mathrm{Cl}$ & $\begin{array}{l}\text { P-value } \\
\text { (CRisk) }\end{array}$ & HR & $95 \%$ Cl & $\begin{array}{l}\text { P-value } \\
\text { (CRRisk) }\end{array}$
\end{tabular}

GSTM1 and GSTT1 genotypes (2 groups)

\begin{tabular}{|c|c|c|c|c|c|c|}
\hline $\begin{array}{l}\operatorname{GSTM} 1(+) / \operatorname{GSTT1}(+) \text { and GSTM1 }(-/-) / G S T T 1(+) \text { and GSTM1(+) } \\
/ \operatorname{GSTT1}(-/-)^{(N=77)}\end{array}$ & Reference & 1 & 0.002 & Reference & 1 & $1.9 \times 10^{-5}$ \\
\hline $\operatorname{GSTM1}(-/)$ and $\operatorname{GSTT1}(-/-)^{(N=9)}$ & 7.190 & $\begin{array}{l}(2.165- \\
23.874)\end{array}$ & & 6.521 & $\begin{array}{l}(2.758- \\
15.420)\end{array}$ & \\
\hline
\end{tabular}

Diagnosis

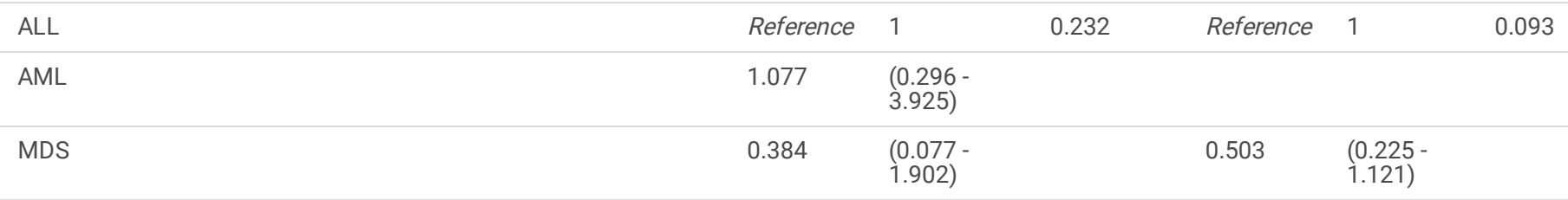

Cum_AUC $(m g * h / L)^{\#}$

$\begin{array}{lllrrr}<59.2 & \text { Reference } & 1 & 0.062 & \text { Reference } & 1 \\ 59.2-98.6 & 3.891 & (1.327- & 0.220 & 3.947 & (0.432- \\ & & 11.409) & 36.040) & \\ >98.6 & 1.741 & (0.201- & & \end{array}$

AUC_1stDose $(m g * h / L)$

\begin{tabular}{|c|c|c|c|c|c|}
\hline$<3.7$ & Reference & 1 & 0.090 & Reference & 1 \\
\hline $3.7-6.16$ & 0.729 & $\begin{array}{l}(0.089- \\
5.983)\end{array}$ & & 0.391 & $\begin{array}{l}(0.041 \\
-3.737)\end{array}$ \\
\hline
\end{tabular}

Intensity of conditioning

\begin{tabular}{|c|c|c|c|c|c|c|}
\hline 2 & Reference & 1 & 0.134 & Reference & 1 & 0.100 \\
\hline 3 or more & 0.382 & $\begin{array}{l}(0.086- \\
1.687)\end{array}$ & & 0.338 & $\begin{array}{l}(0.091- \\
1.248)\end{array}$ & \\
\hline
\end{tabular}

Disease phase

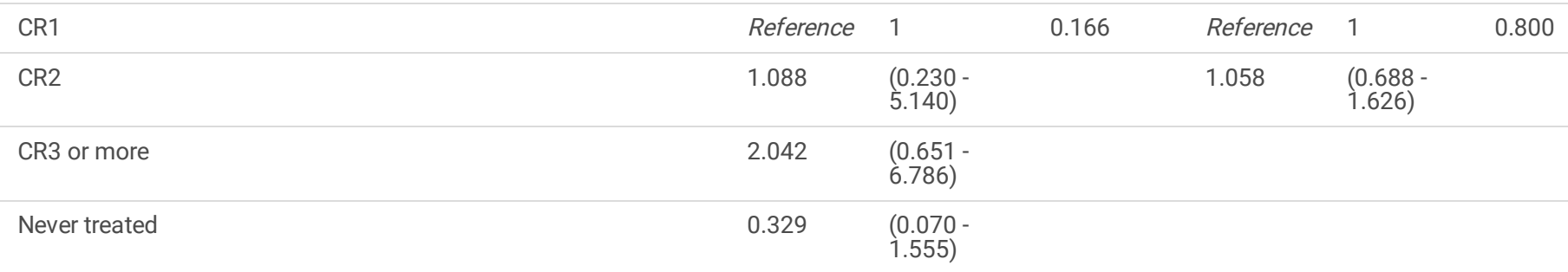

Abbreviations: adj, adjusted; ALL, acute lymphoblastic leukemia; AML, acute myeloid leukemia; AUC_day1, Area under the curve for BU after the first dose of $\mathrm{BU} ; 95 \% \mathrm{Cl}, 95 \%$ confidence interval; CRisk, competing risk analysis of the cumulative incidence of relapse with competing event death; CRRisk, multivariate competing risk regression analysis that is presented with Fine-Gray proportional hazard ratios (HR); CR1, first complete remission; CR2, second complete remission; CR3, third complete remission; HR, hazard ratio; disease status; CumAUC, Cumulative area under the curve for BU; MDS, myelodysplastic syndrome;

"CR3 or more" included all patients either in CR3 or more or in partial remission or those with $>10 \%$ of circulating myeloblasts before conditioning;

*"Intensity of conditioning", 2 alkylating agents (busulfan with cyclophosphamide or melphalan) and 3 agents (busulfan/cyclophosphamide with Loading [MathJax]/jax/output/CommonHTML/fonts/TeX/fontdata.js 
\# CumAUC was calculated after 16 doses administered in $6 \mathrm{~h}$ intervals and is presented in $\mathrm{mg}$ *h/L of which one dose $3.7 \mathrm{mg}$ ( $\mathrm{h} / \mathrm{L}$ is equivalent to $900 \mathrm{\mu M}$ $\mathrm{x}$ min and $6.16 \mathrm{mg}$ औh/L is equivalent to $1500 \mu \mathrm{M} \times \mathrm{min}$;

Bold, significant p-values below 0.05 .

GSTM1-null and GSTT1-null are presented as GSTM1(-/-) and GSTT1(-/-), respectively. GSTM1 non-null and GSTT1 non-null genotypes are presented as GSTM1(+) and GSTT1(+), respectively.

\section{Figures}

Figure 1A

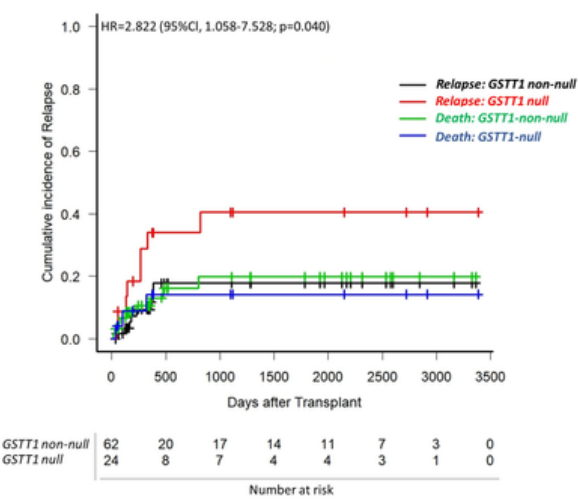

Figure 18

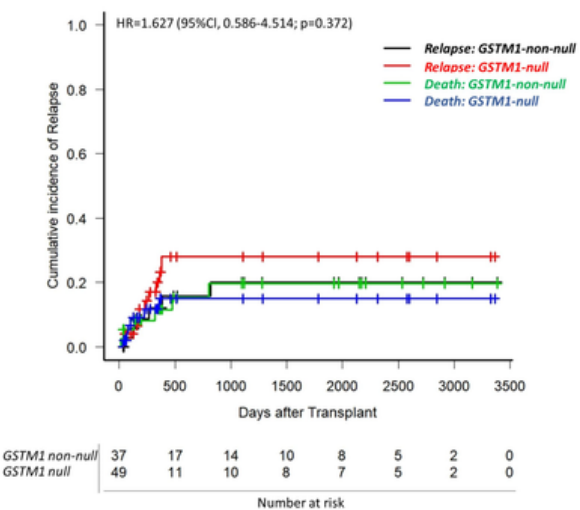

Figure $1 \mathrm{C}$

Figure 10
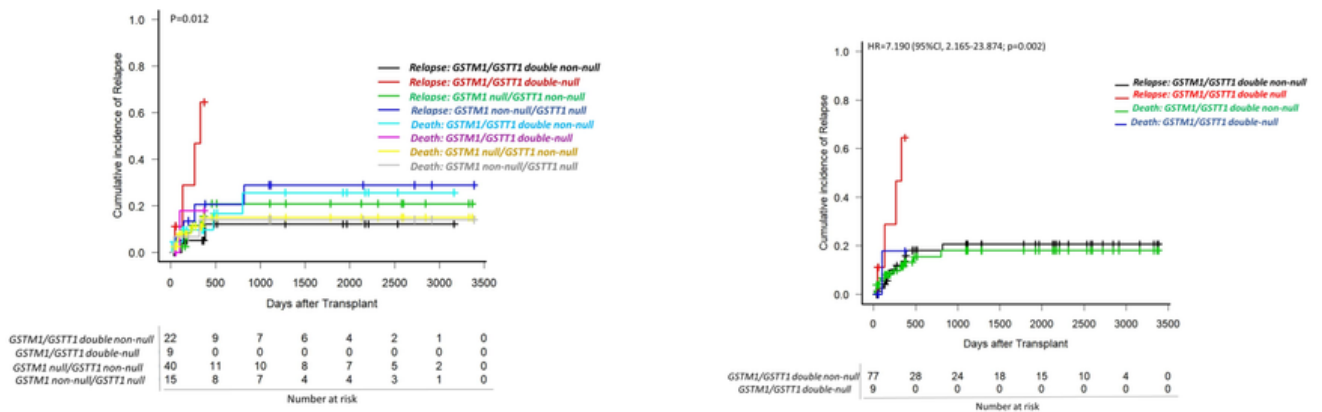

Figure 1

Cumulative incidence plots of relapse (A, B, C, D) in univariable competing risk analyses stratified by GST-null variants Footnote: Results are plotted for (A) GSTT1(-/-) group versus groups GSTT1(+/-) and GSTT1(+/+) together presented as GSTT1(+); (B) GSTM1(-/-) group versus groups GSTM1(+/-) and GSTM1 (+/+) together presented as GSTM1(+); (C.) combined GSTM1(-/-)/GSTT1(-/-) versus grouped other genotype combinations [GSTM1(-/-)/GSTT1(+), GSTM1(+)/GSTT1(-/-) and GSTM1(+)/GSTT1(+)]; (D.) combined GSTM1(-/-)/GSTT1(-/-) versus grouped other combinations [GSTM1(+)/GSTT1(+)]. p- values for the difference in cumulative incidence of relapse were calculated with Gray`s test with death as a competing event. HR, hazard ratio; GSTM1-null and GSTT1-null are presented as GSTM1(-/-) and GSTT1(-/-), respectively. GSTM1 non-null and GSTT1 non-null genotypes are presented as GSTM1(+) and $\operatorname{GSTT1}(+)$, respectively. 


\section{Figure 2}

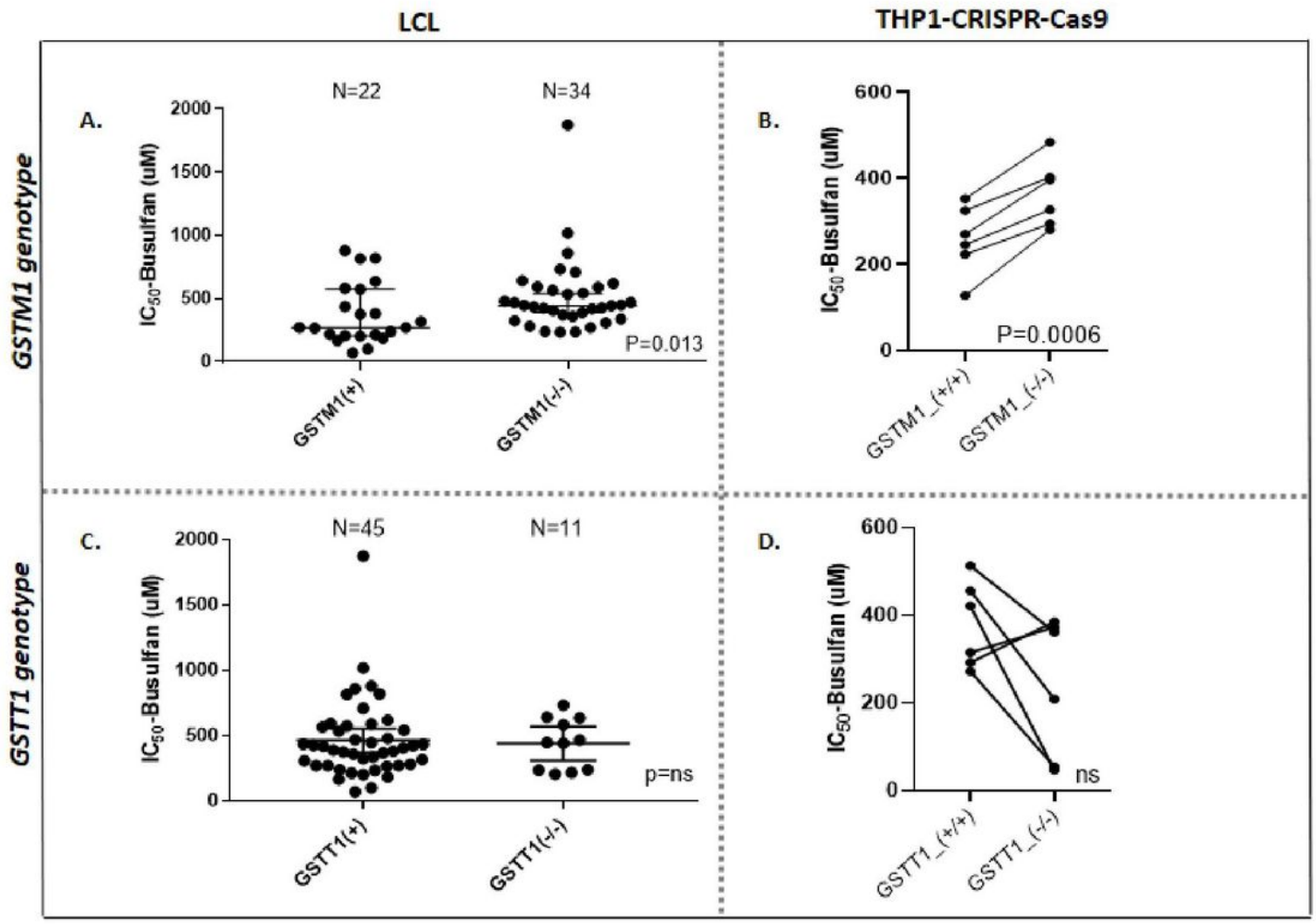

Figure 2

IC50 values for BU stratified according to GSTM1- (A.) and GSTT1- null variants (C.) in LCLs and CRISPR-Cas9 gene-edited THP1GSTM1(-/-) (B.) and THP1GSTT1(-/-) (D.) cell models. Footnote: Concentration-response titration points were fitted to a Hill equation for BU. The $50 \%$ inhibitory concentrations of BU (BU-IC50) were determined by dose-response curve fitting using Prism 5.02 software (GraphPad Softwarelnc., CA. USA). The coefficient of determination (R2) of each plate was used to assess experimental reproducibility and was set to be above 0.95 . Independent experiments were repeated at least three- times. Non-parametric unpaired t-test was used in LCLs (A, C). Pairwise comparisons by t-test between GST(-/-) variants in THP1-CRISPR-Cas9 models (B., D.) were used. In THP1-CRISPR-Cas9 cell models (B., D.), dots represented are specific clones with identified GST(-/-) variants (+/+ vs -/-) based on Sanger DNAsequencing. P-values below 0.05 were considered statistically significant. ns, not significant. GSTM1-null and GSTT1-null are presented as GSTM1(-/-) and GSTT1(-/-), respectively. GSTM1 non-null and GSTT1 non-null genotypes are presented as GSTM1(+) and GSTT1(+), respectively. 


\section{Figure 3}

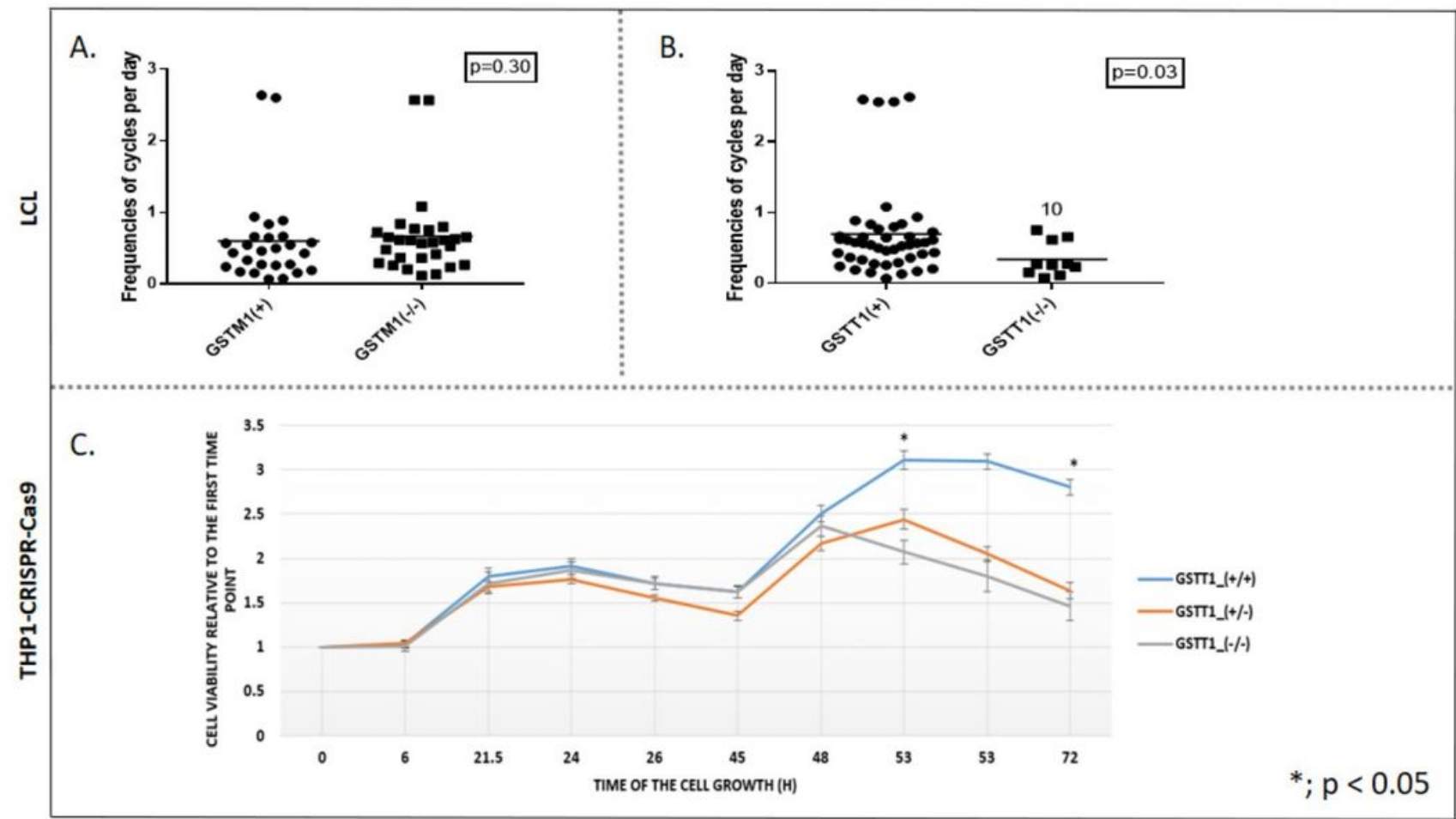

Figure 3

Baseline cell growth against GSTM1-null (A.) and GSTT1-null (B.) genotypes in LCLs; (C.) RealTime Cell Viability assay - Kinetics plot 72h stratified by GSTT1null genotype at baseline (proliferation profile) in THP1GSTT1(-/-) cell models Footnote: (A, B.) On the y-axis, the basal cell growth rate ( $r$ ) was calculated using the following formula, appropriate for the usual exponential kinetics of cell growth ( $N$; the number of cells) after the defined time ( $t$; $h$ ): $\mathrm{Nt}=\mathrm{No} .2 \mathrm{tr} ;(\mathrm{C}$.) Measurement of baseline reducing the potential of viable cells according to GSTT1(-/-) variant in CRISPR-Cas9 gene-edited cell models was performed. The unpaired t-test between GST genotypes in LCLs (A., B.) and Pairwise comparisons by t-test between GSTT1 genotypes in THP1-CRISPR-Cas9 models were used. P-values below 0.05 were considered statistically significant. GSTM1-null and GSTT1-null are presented as GSTM1(-/-) and GSTT1(-/-), respectively. GSTM1 non-null and GSTT1 non-null genotypes are presented as GSTM1(+) and GSTT1(+), respectively. 
Figure 4ABCD

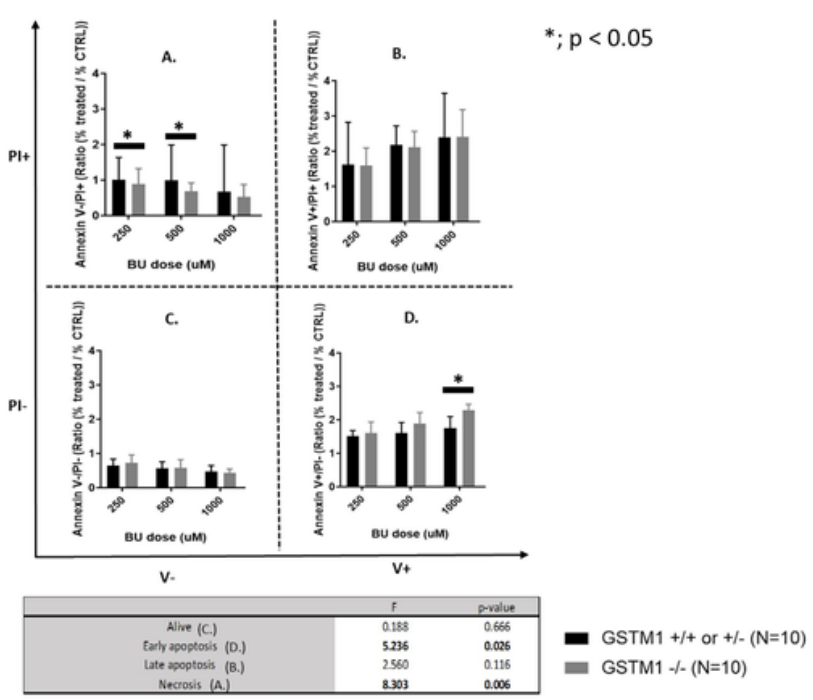

Figure 4E

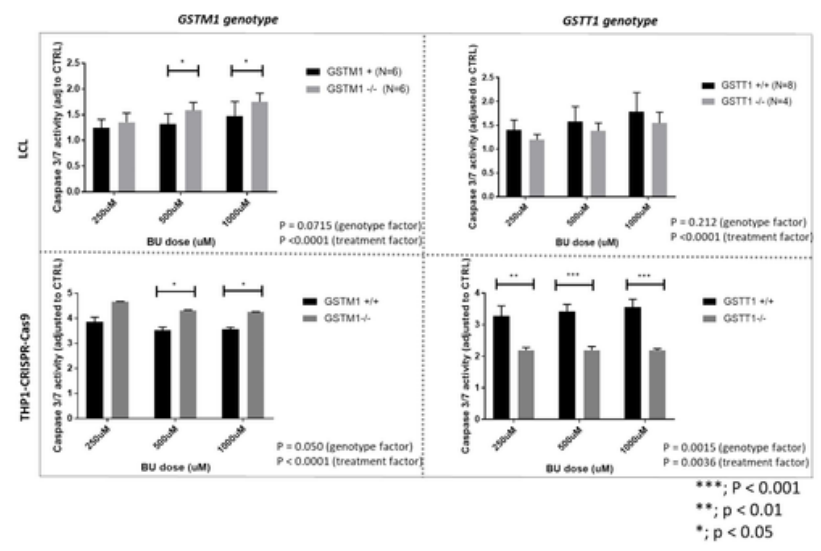

\section{Figure 4}

Flow cytometric analysis (FACS) by using Annexin V/PI assay; primary necrosis (A), late apoptosis (B), live cells (C) and early apoptosis (D) in LCLs stratified according to GSTM1-null variants; and Caspase 3/7 activity (E.) in LCLs and THP-CRISPR-Cas9 models stratified according to GST-null variants at 250, 500 and $1000 \mu \mathrm{M}$ BU $48 \mathrm{~h}$ post-treatment Footnote: Statistical analysis was performed by two-way ANOVA considering 250,500 and $1000 \mu \mathrm{M}$ BU concentrations (genotype and treatment factors); t-tests between GST(-/-) variants in each condition separately were used; no statistically significant differences were observed between GSTM1+ and GSTM1(-/-) LCLs and THP-CRISPR-Cas9 models in either 1\% DMSO or medium only; P-values below 0.05 were considered statistically significant. GSTM1-null and GSTT1-null are presented as GSTM1(-/-) and GSTT1(-/-), respectively. GSTM1 non-null and GSTT1 non-null genotypes are presented as GSTM1(+) and GSTT1(+), respectively. 
Figure 5

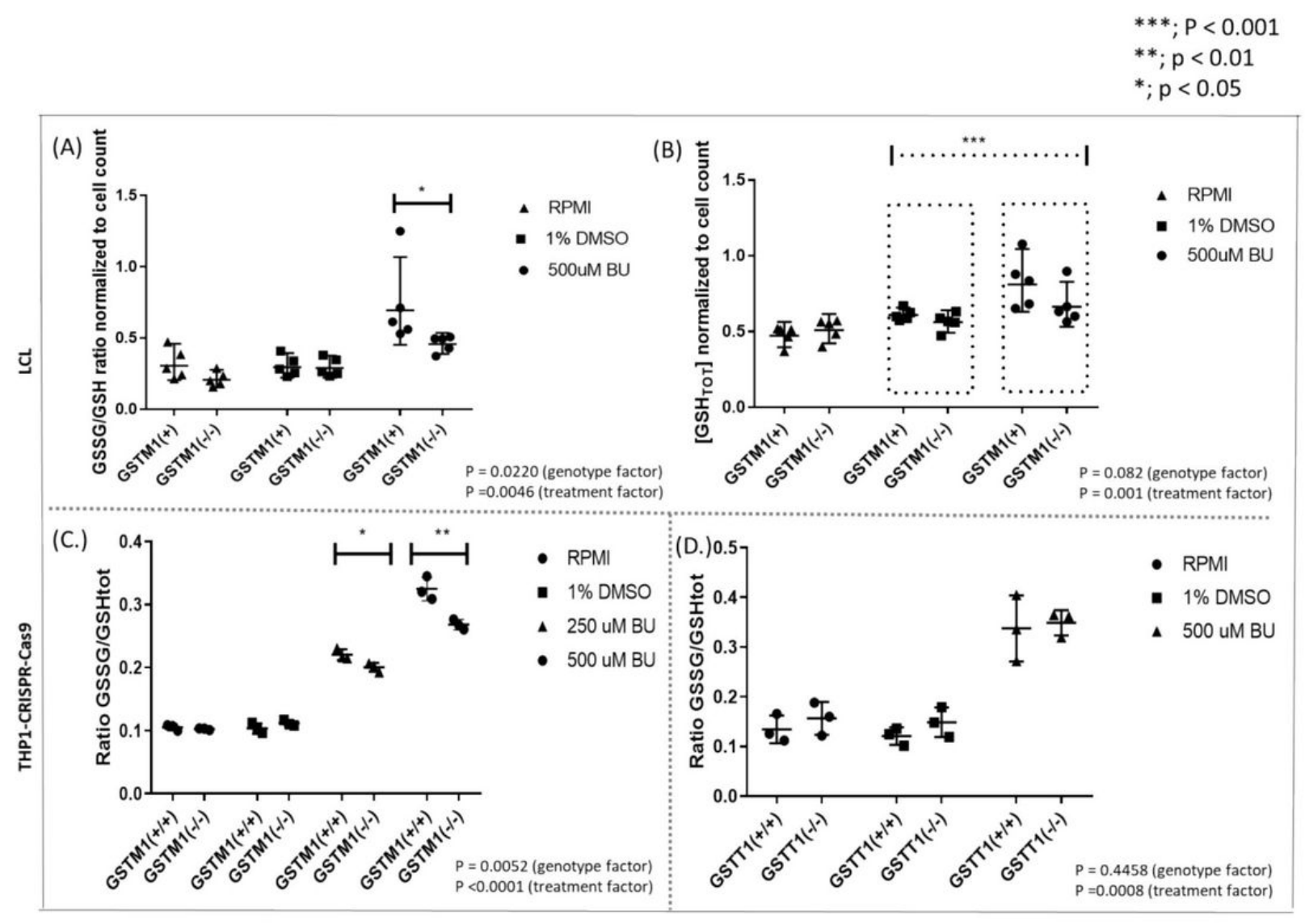

Figure 5

[GSSG/GSHT] ratio (A) and GSHT (B) in LCLs stratified according to GSTM1-null variant; and [GSSG/GSHT] ratios in CRISPR-Cas9 edited THP1GSTM1(-/-) (C.) and THP1GSTT1(-/-) (D.) cell models after the treatment with $500 \mu \mathrm{M}$ BU Footnote: Statistical analysis was performed by the two-way ANOVA considering 250 or $500 \mu \mathrm{M} \mathrm{BU}$ concentration (genotype factor); t-tests between GST(-/-) variants in each condition separately were used; no statistically significant differences were observed between GST(-/-) variants in LCLs and THP-CRISPR-Cas9 models in either $1 \%$ DMSO or medium; P-values below 0.05 were considered statistically significant. GSTM1-null and GSTT1-null are presented as GSTM1(-/-) and GSTT1(-/-), respectively. GSTM1 non-null and GSTT1 non-null genotypes are presented as GSTM1(+) and GSTT1(+), respectively.

\section{Supplementary Files}

This is a list of supplementary files associated with this preprint. Click to download.

- 003JurkovicMlakarM1T1SuppMaterial.docx 